\section{Effect of multidisciplinary prehabilitation-rehabilitation on outcomes after colorectal surgery in elderly patients}

Nicholette Goh, MBBS, Kok-Yang Tan, MBBS, MMED

\section{ORIGINAL ARTICLE}

Department of Surgery, Khoo Teck Puat Hospital, Singapore

\begin{abstract}
Objective. To determine the effect of the start-to-finish programme by comparing outcomes of elderly patients who underwent colorectal surgery before and after introduction of the programme.
\end{abstract}

Methods: Data of consecutive patients aged $\geq 75$ years who underwent major colorectal surgery (open, minimally invasive, elective, or emergency) between February 2007 and November 2015 at our institution were collected prospectively. Postoperative outcomes of patients were compared before and after the July 2013 introduction of the start-to-finish programme. Patients were risk-stratified for decision on whether prehabilitation was required, based on frailty syndrome, weighted Charlson Comorbidity Index, and ambulatory status. Frailty was defined as presentation of three or more of the following criteria: unintentional weight loss, self-reported exhaustion, weakness (grip strength), slow walking speed, and low physical activity. Outcome measures included discharge destination, functional decline in terms of a loss of $\geq 10$ points in the Barthel Index at postoperative week 6, length of hospital stay, postoperative complication in terms of a Clavien-Dindo score of $\geq 3$, and 30-day mortality.

Results: A total of 121 geriatric patients were recruited and followed up for a mean duration of 36 months. Of whom, 49 (40.1\%) were recruited after the introduction of start-to-finish programme in July 2013. 34 (28.1\%) of the 121 patients were determined to be frail. In multivariate analysis, frailty was the only predictor of discharge destination (odds ratio $[\mathrm{OR}]=6.067, \mathrm{p}=0.001$ ). Patients with a Clavien-Dindo score of $\geq 3$ were more likely to have functional decline at postoperative week 6 $(\mathrm{OR}=83.926, \mathrm{p}=0.003)$. The start-to-finish programme $(\mathrm{OR}=0.067$, $\mathrm{p}=0.023)$ and elective surgery $(\mathrm{OR}=0.091, \mathrm{p}=0.024)$ were associated with maintenance of functional. Frailty was associated with discharge to facilities other than home $(\mathrm{OR}=6.067, \mathrm{p}=0.001)$ and a steeper decline on longer-term follow-up.

Conclusion: The start-to-finish programme had a positive effect on reducing functional decline after colorectal surgery. Frail patients and patients with major complications require special attention to mitigate the steep functional decline.

Key words: Colorectal Surgery; Frailty; Rehabilitation
Correspondence to: Nicholette Goh, Department of Surgery, Khoo Teck Puat Hospital, 90 Yishun Central, Singapore 768828. Email: nicholette.goh@mohh.com.sg 


\section{INTRODUCTION}

In 2016, 4.7\% of the Singapore population was aged $>75$ years. Although age is not an independent predictor of operative risk or surgical outcome, ${ }^{1}$ frailty is of greater value in predicting surgical outcome and hospital stay. ${ }^{2}$ Surgical outcomes, functional decline, and discharge destination are important outcome measures of holistic patient care. ${ }^{3}$

Prehabilitation is the process of enhancing the functional capacity of the patient to enable greater tolerance of a stressful event. ${ }^{4}$ In our institution, a start-to-finish multidisciplinary model of care has improved the surgical outcome of elderly patients who underwent major colorectal surgery. ${ }^{5}$ The regimen involves prehabilitation 2 weeks prior to surgery to improve nutrition, muscle strength, respiratory, and cardiovascular reserves, followed by a coordinated enhanced recovery and rehabilitation after surgery. This study aimed to determine the effect of the startto-finish programme by comparing outcomes of elderly patients who underwent colorectal surgery before and after introduction of the programme.

\section{METHODS}

This study was approved by the Domain Specific Review Board of the National Health Group of Singapore. Data of consecutive patients aged $\geq 75$ years who underwent major colorectal surgery (open, minimally invasive, elective, or emergency) between February 2007 and November 2015 at our institution were collected prospectively. Postoperative outcomes of patients were compared before and after the introduction of the start-to-finish programme (since July 2013). Patients were managed through the geriatric surgical service ${ }^{6}$ by a multidisciplinary team.

In the start-to-finish programme, patients were risk-stratified for decision on whether prehabilitation was required, based on frailty syndrome, weighted Charlson Comorbidity Index, and ambulatory status. ${ }^{7,8}$ Patients who underwent emergency operations were included in the postoperative component of coordinated enhanced recovery and rehabilitation.

The start-to-finish programme consisted of a multidisciplinary team with a nurse clinician, a physiotherapist, a geriatrician, an anaesthetist, a dietician, and a surgeon. Components of the programme included education and ensuring compliance, cardiovascular strengthening, mobilising, muscle strengthening, and attention to nutrition. ${ }^{5}$ Prehabilitation aims to enable the patients to understand the disease and indication for surgery, to avoid a weight loss of $>5 \%$ over 2 weeks, to achieve $100 \%$ of dietary requirements within 1 week, to improve the number of chair-tostand repetitions by $>10 \%$, and to improve the $10-\mathrm{m}$ walk test in terms of the number of steps and time by $>3 \%$. $^{5}$ The modified Barthel Index was re-evaluated after 2 weeks. Postoperatively, the enhanced recovery programme aims to achieve early discharge home or to a community hospital.

Patients were evaluated pre-operatively, prior to discharge, at postoperative week 6 , and at a mean follow-up of 18 months. Functional status was assessed using the Barthel Index. Discharge destination was stratified based on whether the patients returned to their original accommodation after discharge from the hospital. Other outcome measures included the length of hospital stay, postoperative complication in terms of a ClavienDindo score of $\geq 3,{ }^{9}$ and 30 -day mortality. Functional decline was defined as a loss of $\geq 10$ points in the Barthel Index or mortality at postoperative week $6 .{ }^{9}$ Frailty was defined as presentation of three or more of the following criteria: unintentional weight loss, self-reported exhaustion, weakness (grip strength), slow walking speed, and low physical activity. ${ }^{8} \mathrm{~A}$ negative event was defined as a functional decline of $\geq 20$ points of Barthel Index or death.

Statistical analyses were conducted using SPSS (Windows version 23; IBM Corp, Armonk [NY], US). Continuous variables were analysed using an independent-samples $\mathrm{t}$ test, whereas categorical variables were analysed using the Chi-squared test or Fisher's exact test. Survival was based on the Kaplan-Meier analysis. A p value of $<0.05$ was considered statistically significant.

\section{RESULTS}

A total of 121 geriatric patients were recruited and followed up for a mean duration of 36 (standard deviation, 24) months (TABLE 1). Of the 121 patients, $49(40.1 \%)$ were recruited after the introduction of start-to-finish programme in July 2013; and 34 (28.1\%) were considered to be frail. 
TABLE 1

Patient characteristics $(n=121)$

\begin{tabular}{|c|c|}
\hline Patient characteristic & $\begin{array}{c}\text { No. }(\%) \text { of } \\
\text { patients or } \\
\text { mean } \pm \text { SD }\end{array}$ \\
\hline Male & $69(57.0)$ \\
\hline Female & $52(43.0)$ \\
\hline Age, y & $80.92 \pm 74.97$ \\
\hline \multicolumn{2}{|l|}{ American Society of Anesthesiologists score } \\
\hline$<3$ & $53(43.8)$ \\
\hline$\geq 3$ & $68(56.2)$ \\
\hline \multicolumn{2}{|l|}{ Weighted Charlson Comorbidity Index } \\
\hline$<4$ & $82(67.8)$ \\
\hline$\geq 4$ & $39(32.2)$ \\
\hline \multicolumn{2}{|l|}{ Frailty } \\
\hline Yes & $34(28.1)$ \\
\hline No & $87(71.9)$ \\
\hline Pre-operative Barthel Index & $93.66 \pm 45.100$ \\
\hline \multicolumn{2}{|l|}{ Introduction of start-to-finish programme } \\
\hline Before & $72(59.5)$ \\
\hline After & $49(50.5)$ \\
\hline \multicolumn{2}{|l|}{$\begin{array}{l}\text { Physiological and operative severity score for } \\
\text { the enumeration of mortality and morbidity } \\
\text { (mean \%) }\end{array}$} \\
\hline Predicted mortality & $13.8(0.7-42.3)$ \\
\hline Predicted morbidity & $48.1(2.8-73.1)$ \\
\hline Predicted mortality (colorectal surgery) & $8.29(4.3-97.9)$ \\
\hline \multicolumn{2}{|l|}{ Urgency of surgery } \\
\hline Elective & $100(82.6)$ \\
\hline Emergency & $21(17.4)$ \\
\hline \multicolumn{2}{|l|}{ 30-day mortality } \\
\hline Yes & $3(2.5)$ \\
\hline No & $118(97.5)$ \\
\hline \multicolumn{2}{|l|}{ Postoperative complications } \\
\hline Clavien-Dindo score of $<3$ & $111(91.7)$ \\
\hline Clavien-Dindo score of $\geq 3$ & $10(9.3)$ \\
\hline \multicolumn{2}{|l|}{$\begin{array}{l}\text { Unplanned readmissions within } 2 \text { weeks of } \\
\text { surgery }\end{array}$} \\
\hline Yes & $6(5.1)$ \\
\hline No & $109(94.9)$ \\
\hline \multicolumn{2}{|l|}{$\begin{array}{l}\text { Functional decline (loss of Barthel Index of } \\
\geq 10 \text { ) at postoperative week } 6\end{array}$} \\
\hline Yes & $9(7.4)$ \\
\hline No & $112(92.6)$ \\
\hline Barthel Index at postoperative week 6 & $92.7 \pm 45.10$ \\
\hline Length of hospital stay, d & $10.8 \pm 3.96$ \\
\hline
\end{tabular}

Three $(2.5 \%)$ patients died within 30 days of surgery; 11 (9.3\%) patients had a Clavien-Dindo score of $\geq 3$. The median length of hospital stay was 7 days. Six (5.1\%) patients had an unplanned readmission within 2 weeks of discharge.
Of the 121 patients, 98 (81.0\%) were discharged home or to their original accommodation. Frail patients were less likely to be discharged home (61.8\% vs $88.5 \%, p=0.010$, TABLE 2). Nine $(7.4 \%)$ patients had functional decline at postoperative week 6; functional decline was more likely in patients with a Clavien-Dindo score of $\geq 3$ ( $40.0 \%$ vs $4.5 \%$, $\mathrm{p}=0.003)$ and those with emergency surgery $(23.8 \%$ vs $4.0 \%, \mathrm{p}=0.002)$.

In multivariate analysis, frailty remained the only predictor of discharge destination (odds ratio $[\mathrm{OR}]=6.067, \mathrm{p}=0.001, \mathrm{~T}_{\mathrm{ABLE}}$ 3). Patients with a Clavien-Dindo score of $\geq 3$ were more likely to have functional decline at postoperative week $6(\mathrm{OR}=83.926, \mathrm{p}=0.003)$. The start-to-finish programme $(\mathrm{OR}=0.067, \mathrm{p}=0.023)$ and elective surgery $(O R=0.091, p=0.024)$ were associated with maintenance of function. Frailty was associated with discharge to facilities other than home $(\mathrm{OR}=6.067$, $\mathrm{p}=0.001$ ). Subgroup analysis of frail patients revealed that prehabilitation were associated with being discharged home $(90.0 \%$ vs $50.0 \%$, $\mathrm{p}=0.032)$. In Kaplan-Meier analysis, frail patients had a steeper functional decline rate $(p=0.022$, Figure)

\section{DISCUSSION}

Frailty is a clinical syndrome (determined by weight loss, gait speed, grip strength, physical activity, and physical exhaustion) pertinent to postoperative outcomes. In elderly patients, frailty is associated with increased postoperative morbidity and mortality. ${ }^{2,10-13}$ Frail patients recover less quickly from illness/surgery and are characterised by decreased physiological reserve. ${ }^{14}$

Patient-centred care has recently become a main goal for health care providers. Patient-centred outcomes address the functional decline, increased care needs, and discharge to a nursing home that results in loss of independence. These outcomes are associated with postoperative readmissions and death after discharge. ${ }^{15}$ In a study of critically ill patients aged $>60$ years and their treatment preferences, a significant proportion of patients would decline treatment if it resulted in functional and cognitive loss. ${ }^{16}$ Quality of life is most important to geriatric patients following cancer treatment and should be taken into account when evaluating treatment plans and outcomes. ${ }^{17}$ 
TABLE 2

Variables associated with discharge home and functional decline at postoperative week 6

\begin{tabular}{|c|c|c|c|c|c|c|}
\hline \multirow[t]{2}{*}{ Variable } & \multicolumn{2}{|c|}{$\begin{array}{l}\text { Discharge home } \\
\text { No. (\%) of patients }\end{array}$} & \multirow[t]{2}{*}{$\mathrm{p}$ Value } & \multicolumn{2}{|c|}{$\begin{array}{l}\text { Functional decline } \\
\text { No. (\%) of patients }\end{array}$} & \multirow[t]{2}{*}{$\mathrm{p}$ Value } \\
\hline & Yes & No & & Yes & No & \\
\hline Total & $98(81.0)$ & $23(19.0)$ & & $9(7.4)$ & $112(92.6)$ & \\
\hline Gender & & & 0.378 & & & 0.544 \\
\hline Male & $44(84.6)$ & $8(15.4)$ & & $3(5.8)$ & $49(94.2)$ & \\
\hline Female & $54(78.3)$ & $15(22.7)$ & & $6(4.3)$ & $63(95.7)$ & \\
\hline Frailty & & & 0.010 & & & 0.057 \\
\hline Yes & $21(61.8)$ & $13(38.2)$ & & $5(14.7)$ & $29(85.3)$ & \\
\hline No & $77(88.5)$ & $10(11.5)$ & & $4(4.6)$ & $83(95.4)$ & \\
\hline Introduction of start-to-finish programme & & & 0.275 & & & 0.339 \\
\hline Before & $56(77.8)$ & $16(22.2)$ & & $4(5.6)$ & $68(94.4)$ & \\
\hline After & $42(85.7)$ & 7 (15.3) & & $5(10.2)$ & $44(89.8)$ & \\
\hline Postoperative Clavien-Dindo score & & & 0.095 & & & 0.003 \\
\hline$<3$ & $92(82.9)$ & $19(17.1)$ & & $5(4.5)$ & $106(95.5)$ & \\
\hline$\geq 3$ & $6(60.0)$ & $4(40.0)$ & & $4(40.0)$ & $6(60.0)$ & \\
\hline Urgency of surgery & & & 0.066 & & & 0.002 \\
\hline Elective & $84(84.0)$ & $16(16.0)$ & & $4(4.0)$ & $96(96.0)$ & \\
\hline Emergency & $14(66.7)$ & 7 (33.3) & & $5(23.8)$ & 16 (76.2) & \\
\hline
\end{tabular}

TABLE 3

Multivariate analysis for predictors for discharge home and functional decline at postoperative week 6

\begin{tabular}{|c|c|c|c|c|}
\hline \multirow[t]{2}{*}{ Variable } & Discharge home & \multirow[t]{2}{*}{ p Value } & Functional decline & \multirow[t]{2}{*}{$\mathrm{p}$ Value } \\
\hline & $\begin{array}{l}\text { Odds ratio (95\% } \\
\text { confidence interval) }\end{array}$ & & $\begin{array}{c}\text { Odds ratio (95\% } \\
\text { confidence interval) }\end{array}$ & \\
\hline Weighted Charlson Comorbidity Index of $\geq 4$ & $1.322(0.386-4.521)$ & 0.657 & $1.132(0.155-8.250)$ & 0.903 \\
\hline American Society of Anesthesiologists score of $\geq 3$ & $1.714(0.562-5.230)$ & 0.344 & $0.839(0.133-5.300)$ & 0.852 \\
\hline Frailty & $6.067(2.002-18.383)$ & 0.001 & $0.199(0.029-1.353)$ & 0.099 \\
\hline Elective surgery & $1.772(0.510-6.158)$ & 0.368 & $0.091(0.011-0.726)$ & 0.024 \\
\hline Introduction of start-to-finish programme & $1.270(0.293-5.506)$ & 0.750 & $0.067(0.006-0.690)$ & 0.023 \\
\hline Clavien-Dindo score of $\geq 3$ & $0.252(0.49-1.298)$ & 0.099 & 83.926 (5.573-1263.797) & 0.001 \\
\hline
\end{tabular}

Our previous study focused on the short-term surgical outcomes before and after introduction of the start-to-finish programme. ${ }^{5}$ The present study focused on the impact of frailty on the longer term functional outcomes. The results show that frailty was associated with discharge to an institution instead of home after surgery (including elective), consistent with other studies. ${ }^{18,19}$ Health care costs are reduced when patients can return home with satisfactory functional outcome rather than requiring rehabilitation at an institution. Functional decline was associated with emergency surgery and presence of postoperative complications, whereas prehabilitation was associated with better functional outcome. Prehabilitation aims to maximise patients' functional status preoperatively in order to improve recovery. Frailty is a dynamic state that can be improved through interventions such as exercise. ${ }^{20-22}$ A comprehensive geriatric assessment significantly

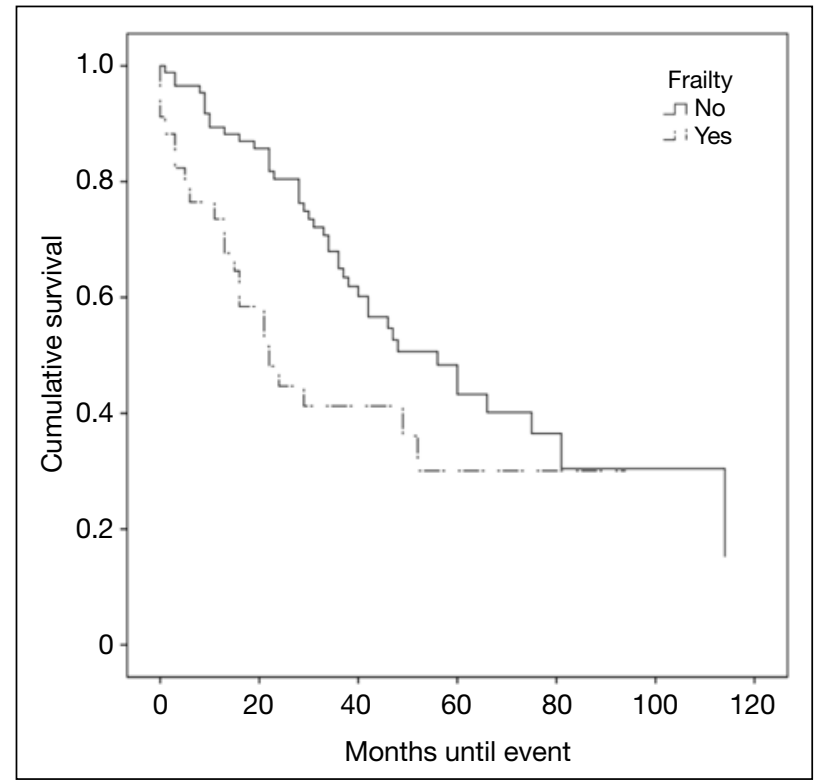

Figure. Kaplan Meier curves of patients with and without pre-operative frailty in terms of functional decline (a loss of Barthel Index of $\geq 20$ ) or death 
reduces medical complications and hospital stay. ${ }^{23}$ In our institution, the geriatric surgical service has decreased morbidity and mortality in geriatric patients, ${ }^{5}$ and the prehabilitation programme has shortened the length of hospitalisation. ${ }^{6}$ Currently, there is no protocol to guide prehabilitation, but several randomised controlled trials on prehabilitation are underway. ${ }^{24,25}$ Nonetheless, frailty does not take cognitive aspects into account, and both frailty and cognitive impairment are predictors of postoperative survival. ${ }^{26}$ Reduced cognitive reserve affects patient judgement of care needs. Preoperative cognitive intervention has been reported to improve postoperative cognitive function. ${ }^{25,27}$

\section{CONCLUSION}

The start-to-finish programme had a positive effect on reducing functional decline after colorectal surgery. Frail patients and patients with major complications require special attention to mitigate the steep functional decline.

\section{ACKNOWLEDGEMENT}

We thank our colorectal specialty nurses for assisting collection of data.

\section{DECLARATION}

The authors did not receive any form of sponsorship and have no conflicts of interest to disclose and no potential financial and non-financial interest to declare.

\section{REFERENCES}

1. Tan KY, Kawamura Y, Mizokami K, et al. Colorectal surgery in octogenarian patients-outcomes and predictors of morbidity. Int J Colorectal Dis 2009;24:185-9. Crossref

2. Lin HS, Watts JN, Peel NM, Hubbard RE. Frailty and postoperative outcomes in older surgical patients: a systematic review. BMC Geriatr 2016;16:157. Crossref

3. Chee J, Tan KY. Outcome studies on older patients undergoing surgery are missing the mark. J Am Geriatr Soc 2010;58:223840. Crossref

4. Topp R, Ditmyer M, King K, Doherty K, Hornyak J 3rd. The effect of bed rest and potential of prehabilitation on patients in the intensive care unit. AACN Clin Issues 2002;13:263-76. Crossref

5. Chia CL, Mantoo SK, Tan KY. 'Start to finish trans-institutional transdisciplinary care': a novel approach improves colorectal surgical results in frail elderly patients. Colorectal Dis 2016;18:4350. Crossref

6. Tan KY, Tan P, Tan L. A collaborative transdisciplinary "geriatric surgery service" ensures consistent successful outcomes in elderly colorectal surgery patients. World J Surg 2011;35:1608-14. Crossref
7. Charlson ME, Pompei P, Ales KL, MacKenzie CR. A new method of classifying prognostic comorbidity in longitudinal studies: development and validation. J Chronic Dis 1987;40:373-83. Crossref

8. Fried LP, Tangen CM, Walston J, et al. Frailty in older adults: evidence for a phenotype. J Gerontol A Biol Sci Med Sci 2001;56:M146-56. Crossref

9. Dindo D, Demartines N, Clavien PA. Classification of surgical complications: a new proposal with evaluation in a cohort of 6336 patients and results of a survey. Ann Surg 2004;240:205-13. Crossref

10. Farhat JS, VelanovichV, Falvo AJ, et al. Are the frail destined to fail? Frailty index as predictor of surgical morbidity and mortality in the elderly. J Trauma Acute Care Surg 2012;72:1526-31. Crossref

11 Makary MA, Segev DL, Pronovost PJ, et al. Frailty as a predictor of surgical outcomes in older patients. J Am Coll Surg 2010;210:9018. Crossref

12. Robinson TN, Eiseman B, Wallace JI, et al. Redefining geriatric preoperative assessment using frailty, disability and co-morbidity. Ann Surg 2009;250:449-55. Crossref

13. Tan KY, Kawamura YJ, Tokomitsu A, Tang T. Assessment for frailty is useful for predicting morbidity in elderly patients undergoing colorectal cancer resection whose comorbidities are already optimized. Am J Surg 2012;204:139-43. Crossref

14. Clegg A, Young J, Iliffe S, Rikkert MO, Rockwood K. Frailty in elderly people. Lancet 2013;381:752-62. Crossref

15. Berian JR, Mohanty S, Ko CY, Rosenthal RA, Robinson TN. Association of loss of independence with readmission and death after discharge in older patients after surgical procedures. JAMA Surg 2016;151:e161689. Crossref

16. Fried TR, Bradley EH, Towle VR, Allore H. Understanding the treatment preferences of seriously ill patients. $N$ Engl $\mathrm{J} \mathrm{Med}$ 2002;346:1061-6. Crossref

17. McKenna RJ Sr. Clinical aspects of cancer in the elderly. Treatment decisions, treatment choices, and follow-up. Cancer 1994;74(7 Suppl):2107-17.

18. Robinson TN, Wallace JI, Wu DS, et al. Accumulated frailty characteristics predict postoperative discharge institutionalization in the geriatric patient. J Am Coll Surg 2011;213:37-44. Crossref

19. Robinson TN, Wu DS, Pointer L, Dunn CL, Cleveland JC Jr, Moss M. Simple frailty score predicts postoperative complications across surgical specialties. Am J Surg 2013;206:544-50. Crossref

20. Gill TM, Gahbauer EA, Allore HG, Han L. Transitions between frailty states among community-living older persons. Arch Intern Med 2006;166:418-23. Crossref

21. Chin A Paw MJ, van Uffelen JG, Riphagen I, van Mechelen W. The functional effects of physical exercise training in frail older people: a systematic review. Sports Med 2008;38:781-93. Crossref

22. Theou O, Stathokostas L, Roland KP, et al. The effectiveness of exercise interventions for the management of frailty: a systematic review. J Aging Res 2011;2011:569194. Crossref

23. Harari D, Hopper A, Dhesi J, Babic-Illman G, Lockwood L, Martin F. Proactive care of older people undergoing surgery ('POPS'): designing, embedding, evaluating and funding a comprehensive geriatric assessment service for older elective surgical patients. Age Ageing 2007;36:190-6. Crossref

24. Abdullah HR, Lien VP, Ong HK, et al. Protocol for a single-centre, randomised controlled study of a preoperative rehabilitation bundle in the frail and elderly undergoing abdominal surgery. BMJ Open 2017;7:e016815. Crossref

25. Wong SG, Maida E, Harvey D, Wagner N, Sonnadara R, Amin N. Evaluation of a physiatrist-directed prehabilitation intervention in frail patients with colorectal cancer: a randomised pilot study protocol. BMJ Open 2017;7:e015565. Crossref

26. Makhani SS, Kim FY, LiuY, et al. Cognitive impairment and overall survival in frail surgical patients. J Am Coll Surg 2017;225:590600. Crossref

27. Saleh AJ, Tang GX, Hadi SM, et al. Preoperative cognitive intervention reduces cognitive dysfunction in elderly patients after gastrointestinal surgery: a randomized controlled trial. Med Sci Monit 2015;21:798-805. Crossref 